\title{
Novel Artificial Ornamental Stone Developed with Quarry Waste in Epoxy Composite ${ }^{\dagger}$
}

\author{
Elaine Aparecida Santos Carvalho ${ }^{a}$, Natália de Figueiredo Vilela ${ }^{a}$,Sergio Neves Monteiro ${ }^{b}$ (D), \\ Carlos Maurício Fontes Vieira ${ }^{a}$ Luís Carlos da Silva ${ }^{b}$ \\ ${ }^{a}$ Universidade Estadual do Norte Fluminense Darcy Ribeiro (UENF), Av. Alberto Lamego, 2000, \\ Campos dos Goytacazes, 28013-602, Rio de Janeiro, RJ, Brasil \\ ${ }^{b}$ Departamento de Ciência e Tecnologia, Instituto Militar de Engenharia (IME), Praça General \\ Tibúrcio, 80, Praia Vermelha, 22290-270, Rio de Janeiro, RJ, Brasil
}

Received: December 18, 2017; Revised: May 13, 2018; Accepted: July 11, 2018

\begin{abstract}
Ornamental stones, such as marble and granite, are worldwide used as pavement cover and lining parts in civil construction. Dwindling deposits and environmental pollution, due to extraction methods, have motivated the replacement of natural ornamental stones by synthetic ones. In particular, artificial ornamental stones are being developed with mineral wastes incorporated into polymeric matrix. In this work, granite particle waste, from a quarry, which supplies plates for building construction, was used in amounts of 85 and $90 \mathrm{wt} \%$ together with epoxy resin to fabricate novel artificial stones. Physical and mechanical characterization disclosed superior properties that allow these new developed artificial stones to be applied as pedestrian traffic pavements.
\end{abstract}

Keywords: Artificial stone, granite particles, quarry waste, mechanical properties, microstructure.

\section{Introduction}

The reuse of industrial residues is attracting interest for research and development of novel materials. In particular, mineral residues that are commonly discarded in the environment are today considered as relevant sources of raw materials ${ }^{1}$. The increasing amount of these residues, treated as worthless wastes, due to inefficient technological management, is causing worrisome pollution. In most cases, inorganic mineral wastes have a valorization potential associated with both energy saving and development of new produts ${ }^{1-2}$. A typical case is that of ornamental stone production. These stones, such as marble and granite, are produced as plates in mineral quarries by explosion, sawing and polishing methods that generate a considerable amount of fragments with different sizes ${ }^{3}$. Larger fragments with particle size greater than $3.2 \mathrm{~mm}$, are classified as pebbles and commercialized for concrete fabrication. By contrast smaller particles are considered wastes and thrown away from the operational industrial area.

In Brazil, the environmental impact caused by the wastes from queries is becoming a relevant issue and demanding solutions based on reuse alternatives. A possible solution is the production of artificial stones with elevated percentage of fine mineral wastes bound with either clay, cement or polymeric resin ${ }^{4-10}$. In additional to these experimental works, similar artificial stones as engineering composites using waste fragments incorporated into distinct matrices have been reported ${ }^{11-16}$. Lee et $\mathrm{al}^{11}$ recycled $55 \%$ of granite fragments and $37 \%$ of waste glass powder mixed with

*e-mail: snevesmonteiro@gmail.com

Article presented in the ABM Week 2017, October 2nd to 6th, 2017, São

Paulo, SP, Brazil unsaturated polyester to fabricate artificial stone slabs with density of $2.445 \mathrm{~g} / \mathrm{cm}^{3}$. Hamoush et al ${ }^{12}$ manufactured an improved engineered artificial stone consisting of two layers, both using polyester matrix incorporated with waste particles. The face layer was made strong, durable, colored, and smooth or textured for natural beauty look. The back layer was lighter and impact resistant with low thermal conductivity for better insulation at lower cost. Santos et $\mathrm{al}^{13}$ compared three types pf Portuguese commercially available engineered artificial stones with natural limestone and granite. The artificial stones were composites made with mineral compound particles in about $10 \%$ polyester matrix. The results indicated that these artificial stones perform adequately in the temperature range from 20 of $200^{\circ} \mathrm{C}$ and are strong competitors to natural stones. Sarabiyik et $\mathrm{al}^{14}$ studied the effect of waste glass powder on polyester matrix composite, known as polymer concrete properties. They found significant increase in mechanical properties as compared to cement concrete for civil construction. ElBashir et $\mathrm{al}^{15}$ characterized the technological properties of polymethylmethacrylate, PMMA, nanocomposites filled with waste stones of marble, granite and basalt for construction application in the marmoreal artificial stone industry. The main point of interest was the decorative effect of alabaster of this artificial stone with improved rigidity and abrasion resistance. Ribeiro et a ${ }^{16}$ evaluated the microstructure and mechanical properties of a $10 \%$ polyester matrix composite incorporated with waste marble fragments. This artificial marble presented a less dense microstructure but lower bending and compressive moduli. A density of about $2.3 \mathrm{~g} / \mathrm{cm}^{3}$ was reported for the artificial marble. 
As aforementioned ${ }^{11-16}$, both polyester and PMMA matrix artificial stones can be produced with improved properties related to mechanical resistance as well as low water absorption and density. Indeed, the polymeric resin, while fluid, penetrates in between the mineral particles. This not only provides cohesion but also eliminates natural porosity, which always exist in natural rock particles. The consequent lower water absorption and improved mechanical resistance of an artificial stone, as a two-component composite material, makes it an ideal construction product for floors and pavements ${ }^{11}$. For artificial stone production, polyester has been the choice of a polymeric matrix ${ }^{9,11-16}$. However, a preliminary work ${ }^{6}$ using sintering residue form steelmaking industry indicated a potential for using epoxy as polymeric matrix. In fact, epoxy has slightly higher strength and rigidity than polyester as well as comparative lower density and better ductility. This motivated the present investigation of an artificial stone using epoxy as a binder. The particular interest would be the special rheological properties of epoxy, which might provide improved wear resistance.

Based on the existing experience regarding artificial stones and the increase Brazilian production of ornamental stones ${ }^{17}$, the objective of this work was to develop novel artificial stones for heavy traffic pavements. These artificial stones are composed of high percentage of granite fine particles, as waste from a quarry, embedded in a small percentage of epoxy resin, enough to be the continuous matrix of a composite material.

\section{Materials and Methods}

The granite fine particles waste was collected as tail from a pebble separation process in the Itereré quarry located in the mountain region of Serra da Bela Vista, at $17 \mathrm{~km}$ from the city of Campos dos Goytacazes, north of state of Rio de Janeiro, Brazil. After collection, the waste was subjected to ball milling for further reduction in particle size. By means of dry sieving, the reduced waste was then separated into three granulometric classes, shown in Table 1, according to the ABNT/NBR-7181 Brazilian standard ${ }^{18}$.

The epoxy used as binding for the waste particles was a diglycidyl ether of bisphenol A (DGEBA) resin mixed with stoichiometric 13 parts per hundred of triethylene tetramine (TETA) supplied by Epoxyfiber, Brazil. The supplier indicated density of the epoxy as $1.15 \mathrm{~g} / \mathrm{cm}^{3}$.

Based on the three distinct granulometric classes presented in Table 1, different mixtures of particles sizes were proposed.

Table 1. Granulometric classes used for the production of ornamental stones.

\begin{tabular}{lc}
\hline Civil Construction Denomination & Particle size $(\mathbf{m m})$ \\
\hline Rough & $2.000-0.710$ \\
Medium & $0.710-0.063$ \\
Thin & $<0.063$ \\
\hline
\end{tabular}

The purpose of these 10 mixtures was to obtain the one with maximum dry density using the Simplex-Lattice design. A ternary diagram shown in Fig. 1 illustrates the experimental numeric modeling SIMPLEX network for the 10 different mixtures. Each vertice of the triangle in Fig. 1 corresponds to $100 \%$ : rough $(\mathrm{G})$, medium $(\mathrm{M})$ or fine $(\mathrm{F})$ particles. The other points in the triangle display (in parenthesis) the fractions corresponding to the mixtures. The density of each mixture was calculated according to the ABNT/MB-3388 Brazilian standard ${ }^{19}$.

Artificial stone plates with dimensions of $100 \mathrm{x} 100 \mathrm{x}$ $10 \mathrm{~mm}$ were developed by combining the particle mixture in Fig. 1, found with greatest density, with 10 or $15 \mathrm{wt} \%$ of DGEBA/TETA epoxy inside a steel mold. The mixture was done by hand-laying the waste particles and still fluid epoxy/hardener directly in the mold. A pressure of $10 \mathrm{MPa}$ was applied to the lid of the mold during the curing process at room temperature for 2 hours. The plate was removed from the mold and subjected to post-cure inside an electrical stove at $60^{\circ} \mathrm{C}$ for 5 hours.

From each of the quarry waste-added artificial stone with epoxy matrix, 6 prismatic specimens with dimensions of $25 \times 100 \times 10 \mathrm{~mm}$ were cut and 3 points bend tested in a model 5582 Instron machine as per AENOR EN-14617-2 Spanish standard ${ }^{20}$ and according to the ABNT/NBR-15847 Brazilian standard ${ }^{21}$.

The apparent density and porosity as well as the water absorption of the developed artificial stones were evaluated according to the Brazilian standard ${ }^{21}$ in 10 specimens obtained from each distinct plate. The determination of density, porosity and water absorption started with a sample being dried for moisture release in a Timer, Brazil, stove at $70^{\circ} \mathrm{C}$ until constant mass. This dried sample was then weighted in a Marte, Brazil, scale with 0.01g of precision. Both the dried weight and that after immersion in water were used to evaluate the above-mentioned properties according to calculations and procedures given by the standard ${ }^{21}$.

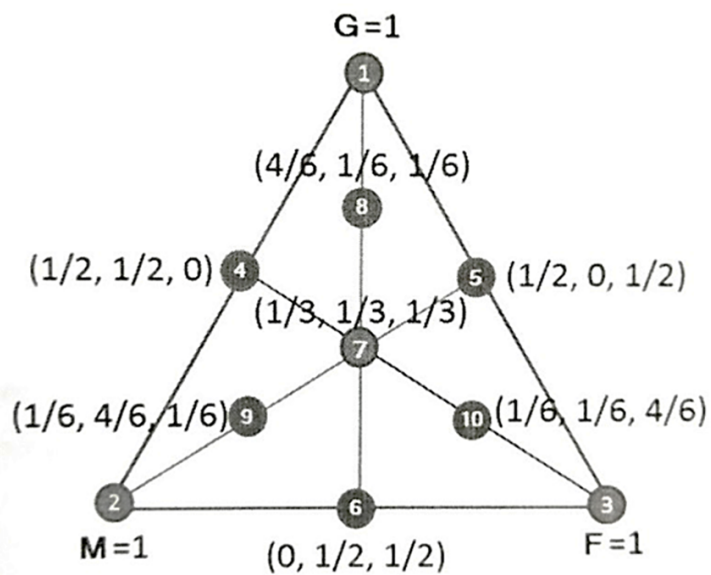

Figure 1. Ternary diagram of the Simplex complete cubic model. 
Wear tests were performed in an Amsler equipment of the Center of Mineral Tecnology, CETEM, in the city of Cachoeiro de Itapemirim, state of Espírito Santo, Brazil. These tests were intended to evaluate the abrasive wearing suffered by $70 \times 70 \times 30 \mathrm{~mm}$ plates of the investigated artificial stones as per ABNT/NBR-12042 Brazilian standard ${ }^{22}$.

The microstructure of the fracture surface of bend-ruptured specimens was analyzed by scanning electron microscopy (SEM) in a model Super Scan SSX-550 Shimadzu microscope operating with secondary electrons at $20 \mathrm{kV}$.

\section{Results and Discussion}

Table 2 presents the weight and density of the dried particle mixtures indicated in Fig. 1. In this table it is highlighted the mixture number $\mathbf{8}$, which displays both the greatest weight and density. Consequently, this mixture also has the highest granite particles close-packing. The mixture number 8 , with $67 \%$ rough, $16 \%$ medium and $16 \%$ fine particles was selected as the most close-packed in spite of different geometric shapes ${ }^{19-24}$.

This mixture was used as the filler for epoxy composites. Indeed, in the case of polymer composites with solid high modulus particulate fillers (rheology of highly concentrated polymer suspensions), the maximum amount of filler that can be physically incorporated into the epoxy matrix is governed, amongst other factors, by the most close-packed mixture of particles corresponding to the maximum volumetric packing fraction (MVPF) of the filler particles. This MVPF value, related to the spatial packing efficiency of the filler particles, corresponds to the minimum amount of matrix required to completely wet all particles surface and fill in all interstitial voids in a most close-packing aggregation of the filler particles. The value of MVPF of a given particulate filler will depend on the particles shape (aspect ratio), its size distribution and specific surface area. So, when the best closepacking aggregate of granite particles is used at 85 or $90 \mathrm{wt}$. $\%$ content in 15 or $10 \mathrm{wt}$. $\%$ of epoxy resin, relatively more fluid matrix is available to wet all granite particles surface

Table 2. Weight and density of the quarry waste particle mixtures.

\begin{tabular}{lcc}
\hline $\begin{array}{l}\text { Mixture Number } \\
\text { in Fig 1 }\end{array}$ & Weight (g) & Density $\left(\mathbf{g} / \mathbf{c m}^{\mathbf{3}}\right)$ \\
\hline 1 & $1.447 \pm 0.013$ & $1.435 \pm 0.010$ \\
2 & $1.703 \pm 0.028$ & $1.688 \pm 0.030$ \\
3 & $1.490 \pm 0.009$ & $1.476 \pm 0.010$ \\
4 & $1.635 \pm 0.015$ & $1.613 \pm 0.015$ \\
5 & $1.817 \pm 0.043$ & $1.793 \pm 0.045$ \\
6 & $1.813 \pm 0.003$ & $1.790 \pm 0.010$ \\
7 & $1.832 \pm 0.041$ & $1.810 \pm 0.044$ \\
$\mathbf{8}$ & $\mathbf{1 . 8 6 7} \pm \mathbf{0 . 0 3 3}$ & $\mathbf{1 . 8 4 3} \pm \mathbf{0 . 0 3 1}$ \\
9 & $1.475 \pm 0.043$ & $1.457 \pm 0.040$ \\
10 & $1.793 \pm 0.013$ & $1.770 \pm 0.010$ \\
\hline
\end{tabular}

and fill in all interstitial voids present in this aggregate of granite particles with epoxy resin system. Thus, this effect reflects directly in the apparent density, apparent porosity and water absorption values of the artificial stone, as shown in Table 3. This table presents the apparent density, water absorption and apparent porosity for the developed artificial stones with 10 and $15 \%$ of epoxy as binding matrix for the mixture 8 (Fig 1 and Table 3 ) of quarry waste particles.

The results in Table 3 indicate that the physical properties of the developed artificial stones are favorable for civil construction applications. Indeed, the current commercial artificial stones possess apparent densities between 2.4 and $2.5 \mathrm{~g} / \mathrm{cm}^{3}{ }^{16}$. The artificial stones in the present work, Table 3, are relatively lower, 2.25 and $2.35 \mathrm{~g} / \mathrm{cm}^{3}$, which means lower transportation costs.

As for the water absorption, industrial artificial marbles are fabricated with 0.09 to $0.40 \%$, depending on vacuum application during processing ${ }^{25}$. The artificial stones developed in the present work were fabricated without vacuum for lower cost and easy processing. Nevertheless, Table 3 shows water absorption values of 0.25 and 0.35 that are within the aforementioned industrial range ${ }^{25}$. It is worth mentioning that Borsellino et $\mathrm{al}^{26}$ found $0.25 \%$ of water absorption, same for $85 \%$ quarry waste in Table 3 , in an artificial stone with marble residues and epoxy.

In terms of apparent porosity, Chiodi Filho and Rodrigue $z^{25}$ indicated that ornamental stones for high quality lining or facing in civil construction should have porosity below 0.54 $\%$. In Table 3 one sees that the developed artificial stone with $85 \%$ quarry waste, within the standard deviation, almost reach this value. In fact, by processing under vacuum the particle mixture with still fluid epoxy resin, the porosity might be reduced.

Figure 2 shows typical flexural stress vs strain curves, obtained from 3 points bend tests, for both developed artificial stones and neat DGEBA/TETA epoxy. In this figure the artificial stone curves are, as expected, almost coincident with only slight difference between the rupture strength; $32 \pm 2 \mathrm{MPa}$ for $85 \%$ and $30 \pm 1$ for $90 \%$ quarry waste/epoxy stones. On the other hand, the neat epoxy is much stronger with $94 \pm$ $5 \mathrm{MPa}$ of rupture stress. By contrast, the bend modulus for both stones, around $15 \mathrm{GPa}$, is significantly higher than that of the neat epoxy, around $2.2 \mathrm{GPa}$. Consequently, the strain

Table 3. Physical properties of apparent density, water absorption and apparent porosity as well as mechanical properties of the investigated artificial stones.

\begin{tabular}{lcc}
\hline Property & $\mathbf{9 0 \%}$ Waste & $\mathbf{8 5 \%}$ Waste \\
\hline Apparent Density $\left(\mathrm{g} / \mathrm{cm}^{3}\right)$ & $2.35 \pm 0.08$ & $2.25 \pm 0.02$ \\
Water Absorption $(\%)$ & $0.35 \pm 0.09$ & $0.25 \pm 0.04$ \\
Apparent Porosity $(\%)$ & $0.81 \pm 0.19$ & $0.55 \pm 0.04$ \\
Flexural Strength $(\mathrm{MPa})$ & $30 \pm 1$ & $32 \pm 3$ \\
Bending Modulus $(\mathrm{GPa})$ & $15 \pm 1$ & $15 \pm 1$ \\
Rupture Strength $(\%)$ & $0.19 \pm 0.10$ & $0.20 \pm 0.05$ \\
\hline
\end{tabular}




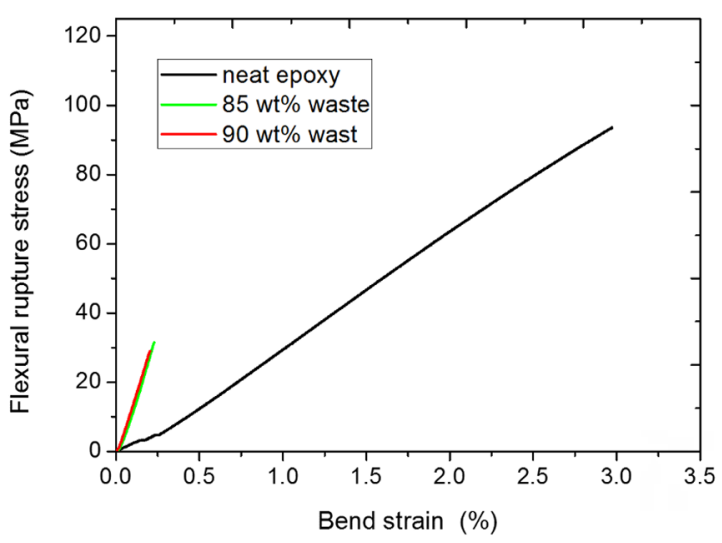

Figure 2. Flexural rupture stress vs bend strain for artificial stones added with quarry waste and neat epoxy.

at rupture of the artificial stones, around $0.2 \%$ is much lower than that of around $3 \%$ for the neat epoxy. These significant differences in behavior can be attributed to the effect that a large number of hard quarry waste particles causes in a relatively small epoxy matrix. From one side the stiffness is controlled by the particles. On the other side the stress is limited by the premature failure due to cracks nucleated at the particle/epoxy interface. This will be further discussed. According to Chiodi Filho and Rodriguez ${ }^{25}$, ornamental stones used as lining and facing in civil construction are considered high resistant materials when the rupture stress exceeds $20 \mathrm{MPa}$, which is the present case. Lee et $\mathrm{al}^{27}$

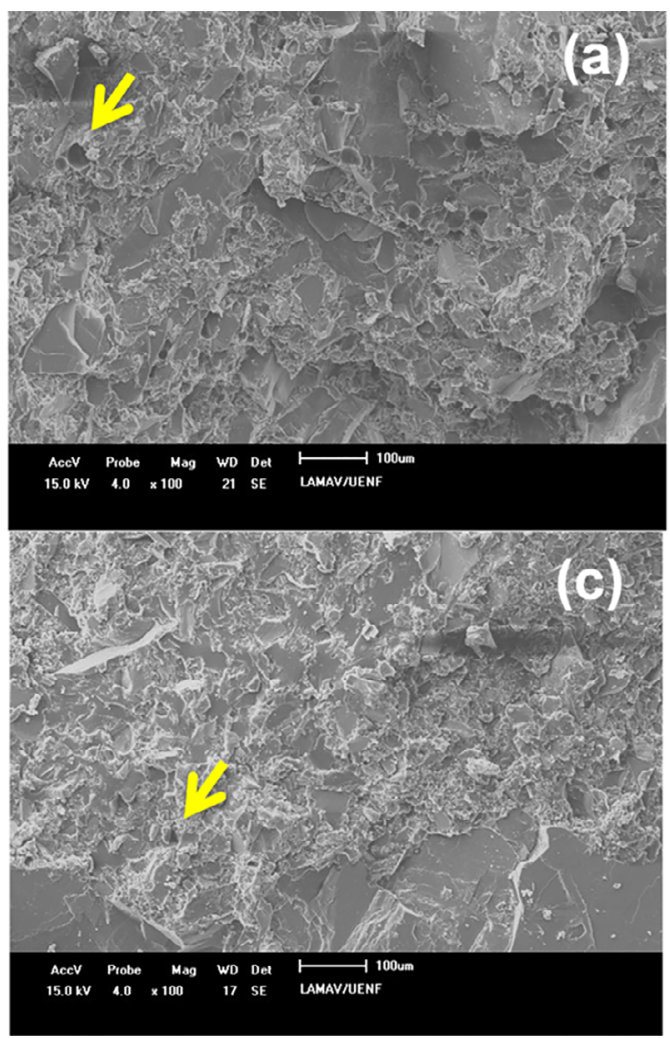

reported $46 \mathrm{MPa}$ for the bend rupture stress of an artificial stone processed under vacuum.

Table 4 presents the reduction in thickness caused by wear tests at two different specimens running distances, 500 and $1,000 \mathrm{~m}$. The results in this table are very similar for both developed artificial stones. Nevertheless, the standards regarding this class of materials fail to indicate limits for related wear tests. Specific parameters for the use of artificial stones in pavements were proposed by Chiodi Filho and Rodrigue ${ }^{25}$ regarding the reduction in thickness obtained from wear tests. According to these authors, pavements with low traffic should display a wear thickness reduction lower than $6 \mathrm{~mm}$; for medium traffic lower than $3 \mathrm{~mm}$; and for heavy traffic lower than $1.5 \mathrm{~mm}^{25}$. Taking into account these parameters, both developed artificial stones might be used even for high traffic pavements.

Figure 3 shows SEM fractographs of bend tested specimens of both developed artificial stones. Despite the relatively small difference in amounts of quarry waste particles, some differences are worth mentioning. The presence of a sensibly greater number of small cavities in the artificial stone with

Table 4. Wear thickness reduction in Amsler tests of artificial stones added with quarry wastes.

\begin{tabular}{lcc}
\hline & \multicolumn{2}{c}{ Wear Thickness Reduction $(\mathbf{m m})$} \\
\hline Running Distance & $500 \mathrm{~m}$ & $1000 \mathrm{~m}$ \\
$90 \%$ quarry waste & $0.66 \pm 0.01$ & $1.37 \pm 0.2$ \\
$85 \%$ quarry waste & $0.57 \pm 0.03$ & $1.39 \pm 0.2$ \\
\hline
\end{tabular}
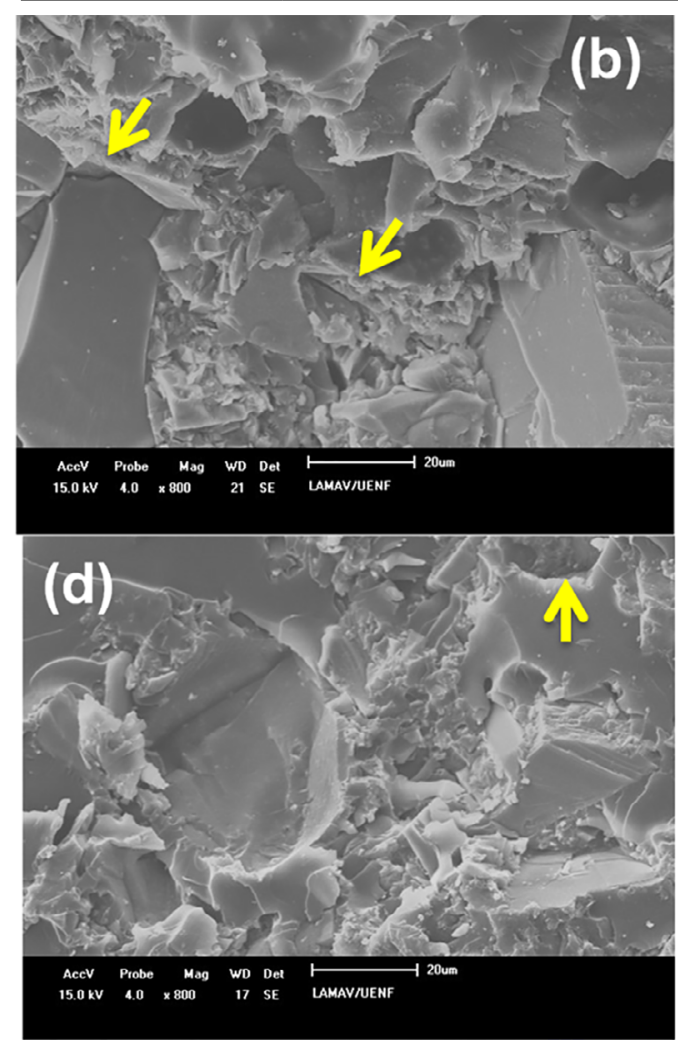

Figure 3. SEM fractographs of the developed artificial stones with addition of quarry waste: (a) $90 \mathrm{wt} \%$ (100x); (b) $90 \mathrm{wt}$ $\%(800 x)$; (c) 85 wt \% (100 x); (d) 85 wt \% (800x). 
90\% particles, Fig 3 (a) and (b), was detected. This justifies its comparatively higher water absorption and apparent porosity, as shown in Table 3.

Another relevant point in Fig. 3 is the existence of cracks associated with the particle/epoxy interface. These cracks are indicated by arrows and tend to promote interfacial debonding, which is responsible for the premature failure of the artificial stones as shown in Fig 2.

\section{Conclusions}

- $\quad$ Artificial stones were successfully developed with 85 and 90 wt \% of waste particles, from a granite quarry, bound with DGEBA/TETA epoxy as a composite matrix.

- A mixture of $67 \%$ of rough, $16 \%$ medium and 16 $\%$ fine waste particles, with the most close-packed condition, allowed the development of relatively higher quality artificial stones, which comply with the industrial requirements for water absorption.

- The flexural rupture stress of both developed artificial stones around $30 \mathrm{MPa}$, lower than that of the epoxy binder, is considered a satisfactory for a high resistant stone used as lining in civil construction.

- The wear parameters revealed that both developed artificial stones could be used as pedestrian heavy traffic pavements.

- $\quad$ SEM fractographs disclosed a sensibly larger amount of small cavities in the $90 \mathrm{wt} \%$ waste added artificial stones. This is responsible for the comparatively higher water absorption and apparent porosity if compared with those values of the $85 \mathrm{wt} \%$ waste quarry artificial stone.

- Cracks associated with particle/epoxy interface are proposed as the mechanism of premature failure of the developed artificial stones that still possess mechanical resistance adequate for specific applications in civil construction.

\section{Acknowledgements}

The authors of the present work wish to thank the Brazilian supporting agencies CAPES, CNPq and FAPERJ for funding and scholarships.

\section{References}

1. Carvalho AC, Pereira FR, Rodrigues Neto JB, Oliveira APN. Industrial waste as alternative raw material for the production of refractory ceramic filters. Cerâmica. 2015;61(359):393-390. (in Portuguese).

2. Areias IR, Vieira CMF, Manhães RST, Intorne AC. Incorporation of sludge of the sewage treatment station (STS) into red ceramic. Cerâmica. 2017;63(367):343-349. (in Portuguese).
3. de Aguiar MC, Gadioli MCB, Babisk MP, Candido VS, Monteiro SN, Vieira CMF. Microstructural Evaluation of a Clay Ceramic Incorporated with Granite Rejects from Stone Sawing Using Diamond Wire. Materials Science Forum. 2014;798-799:251256.

4. Piazzarollo CB, Xavier GC, Alexandre J, Azevedo ARG, Vieira CMF, Monteiro SN, et al. Factorial Design for 32 Experimental Planning of Clay Ceramic Incorporated with Ornamental Stone Waste. Materials Science Forum. 2016;869:127-130.

5. Vieira CMF, Motta TS, Cândido VS, Monteiro SN. Addition of ornamental stone waste to improve distinct formulations of clayey ceramics. Materials Science Forum. 2015;820:419-424.

6. Carvalho EAS, Marques VR, Rodrigues RJS, Ribeiro CEG, Monteiro SN, Vieira CMF. Development of epoxy matrix artificial stone incorporated with sintering residue from steelmaking industry. Materials Research. 2015;18(Suppl 2):235-239.

7. Piazzarollo CB, Xavier GC, Albuquerque FS, Maia PCA, Alexandre $\mathrm{J}$, Azevedo ARG, et al. Statistical analysis of degradation data of red ceramic pieces incorporated with ornamental stone waste. Materials Science Forum. 2015;820:455-461.

8. Ribeiro CEG, Rodriguez RJS, Vieira CMF, Carvalho EA, Candido VS, Monteiro SN. Fabrication of artificial stone from marble residue by resin transfer molding. Materials Science Forum. 2014;775-776:336-340.

9. Ribeiro CEG, Rodriguez RJS, Vieira CMF, Carvalho EA, Candido VS, Monteiro SN. Production of synthetic ornamental marble as a marble waste added polyester composite. Materials Science Forum. 2014;775-776:341-345.

10. Xavier JC, Alexandre J, Maia PCA, Albuquerque FS, Pedroti LG, Azevedo ARG, et al. Resistance to synthetic seawater aggression of clay ceramics incorporated with an ornamental stone residue. Materials Science Forum. 2014;798-799:269274

11. Lee MY, Ko CH, Chang FC, Lo SL, Lin JD, Shan MY, et al. Artificial stone slab production using waste glass, stone fragments and vacuum vibratory compaction. Cement \& Concrete Composites. 2008;30(7):583-587.

12. Hamoush S, Abu-Lebdeh T, Picornell M, Amer S. Development of sustainable engineered stone cladding for toughness, durability, and energy conservation. Construction and Building Materials. 2011;25(10):4006-4016.

13. dos Santos JPL, Rosa LG, Amaral PM. Temperature effects on mechanical behaviour of engineered stones. Construction and Building Materials. 2011;25(1):171-174.

14. Saribiyik M, Piskin A, Saribiyik A. The effects of waste glass powder usage on polymer concrete properties. Construction and Building Materials. 2013;47:840-844.

15. El-Bashir SM, Binhussain MA, Al-Thumairi NA, AlZayed N. Preparation and characterization of PMMA/stone waste nanocomposites for marmoreal artificial stone industry. Reinforced Plastics \& Composites. 2014;33(4):350-357.

16. Ribeiro CEG, Rodriguez RJS, de Carvalho EA. Microstructure and mechanical properties of artificial marble. Construction and Building Materials. 2017;149:149-155. 
17. Brazilian Association of Ornamental Stone Industry (ABIROCHAS). Annual balance of Brazilian exportation and importation of ornamental stones in 2015. Informe 01, 2016. Brasília: ABIROCHAS; 2016. Available from: \&lt;http://www.ivolution.com.br/mais/fotos/6/17/3609/ Informe_01_2016.pdf\&gt;. Access in: 05/12/2017. (in Portuguese).

18. Brazilian Association of Technical Norms (ABNT). NBR-7181 Soil - Grain size analysis. São Paulo: ABNT; 1988. (in Portuguese).

19. Brazilian Association of Technical Norms (ABNT). ABNT/MB 3388 - Soil - Determination of minimum index void ratio of cohesionless soils - Method of test. São Paulo: ABNT; 1991. (in Portuguese)

20. Spanish Association of Norms and Certification (AENOR). UNE-EN 14617-2-Agglomerated stone-Test methods - Part 2: Determination offlexural strength (bending). Madrid: AENOR; 2008. (in Spanish).

21. Brazilian Association of Technical Norms (ABNT). NBR-15845 - Rocks for cladding - Test methods. Anexo F. São Paulo: ABNT; 2010. (in Portuguese).

22. Brazilian Association of Technical Norms (ABNT). NBR-12042 Inorganic materials - Determination of the resistance to abrasion. São Paulo: ABNT; 2013. (in Portuguese).
23. Silva AP, Segadães AM, Devezas TC. Relationship between granulometric distribution, morphology and packing of particles in a real system: High-alumina. In: Proceedings of the 47th Brazilian Congress of Ceramics; 2003 Jun 15-18; João Pessoa, PB, Brazil. p. 150-161. (in Portuguese).

24. Alves HJ, Zauberas RT, Boschi AO. Influence of granulometric distribution of clays on the dry milling yield in a hammer mill. Cerâmica. 2010;56(337):66-70. (in Portuguese).

25. Chiodi Filho C, Rodrigues EP. Guia de Aplicação de Rochas em Revestimentos. São Paulo: Abirochas. 2009. 118 p. (in Portuguese).

26. Borsellino C, Calabrese L, Di Bella G. Effects of powder concentration and type of resin on the performance of marble composite structures. Construction and Building Materials. 2009;23(5):1915-1921.

27. Lee DJ, Shin IJ. Effects of vacuum, mold temperature and cooling rate on mechanical properties of press consolidated glass fiber/PET composite. Composites Part A: Applied Science and Manufacturing. 2002;33(8):1107-1114. 